\title{
AVALIAÇÃO DA LIMPEZA DE UNIDADE DO PACIENTE EM HOSPITAIS DO INTERIOR DO ESTADO DE SÃO PAULO
}

\author{
EVALUATION OF THE PROCEDURES USED FOR DISINFECTING \\ PATIENT'S UNITS IN HOSPITALS OF THE STATE OF SÄO PAULO \\ EVALUACIÓN DE LA LIMPIEZA DE UNIDAD DEL PACIENTE EN \\ HOSPITALES DEL INTERIOR DE SÃO PAULO
}

\author{
Denise de Andrade ${ }^{1}$ \\ Branca Maria de Oliveira Santos ${ }^{2}$ \\ Adriana Serafim Bispo $^{3}$
}

\begin{abstract}
RESUMO:Este estudo objetiva avaliar o procedimento da limpeza de unidade do paciente assim como detectar, apontar e alertar sobre as possiveis falhas nesse processo de limpeza. Os resultados obtidos por entrevistas com os enfermeiros responsáveis pelo Serviço de Enfermagem revelam que o procedimento realizado nos hospitais em estudo năo vem atendendo às normas preconizadas pela literatura o que acarreta um produto final com pouca confiabilidade do ponto de vista da desinfecçăo.
\end{abstract}

PALAVRAS-CHAVE: limpeza de unidade do paciente, desinfecção, infecção hospitalar

\section{INTRODUÇÃO}

Com o avanço científico e tecnológico dos últimos anos na área da saúde é visivel a preocupação com a produção de serviços que têm por finalidade o diagnóstico e a terapêutica, através da reunião de saberes, tecnologias e de profissionais capacitados. Nas relações com a clientela, esses elementos podem desencadear resultados terapêuticos ou iatrogênicos, dependendo da instrumentalização e do encaminhamento das ações, assim como de uma série de fatores relacionados ao ambiente, aos recursos humanos e materiais e ao emprego sistemático de instrumentos e técnicas que atendam à finalidade do trabalho.

Uma das possiveis complicações advindas dessas relações é a infecção hospitalar que tem se constituido num desafio para a equipe multiprofissional de saúde, uma vez que vem se destacando cada vez mais nos últimos anos dentre as causas mais freqüentes de morbimortalidade, com conseqüente ampliação do tempo de permanência do paciente no hospital, aumento do custo de tratamento e menor utilização dos leitos hospitalares.

Embora as principais causas de Infecção Hospitalar estejam relacionadas com o doente suscetivel à infecção e com os métodos diagnósticos e terapêuticos utilizados, não se pode deixar de considerar a parcela de responsabilidade relacionada aos padrões de higiene do ambiente hospitalar, que tem levado a uma preocupação com a sua manutenção terapêutica. Esta preocupação tem sido continua e diligente e tem estado sob responsabilidade da enfermagem desde a atuação de Florence Nightingale, no século XIX, que já enfatizava a necessidade de se diminuir os efeitos negativos que o hospital causava aos pacientes, através do próprio uso do ar,

'Professor Doutor ao Departamento de Enfermagem Geral e Especializada da Escola de Enfermagem de Ribeirão Preto da Universidade de São Paulo.

${ }^{2}$ Professora Livre-Docente junto ao Departamento de Enfermagem Geral e Especializada da Escola de Enfermagem de Ribeirão Preto da Universidade de São Paulo.

${ }^{3}$ Bolsista de Iniciação Científica do Conselho Nacional Científico e Tecnológico - CNPq. 
da limpeza, do silêncio, dentre outras, colocando-os nas melhores condições para a natureza agir (Chairperson, 1980, Nightingale, 1989).

Para a manutenção desse ambiente terapêutico a enfermagem tem procurado organizar e sistematizar o seu conhecimento, sendo as técnicas de enfermagem, voltadas primeiramente para o procedimento a ser executado, uma das alternativas utilizadas para esta finalidade. Nelas aparecem a descrição detalhada de como cada procedimento deve ser realizado, assim como a razão para cada passo, constituindo-se num conjunto de medidas, descritas passo a passo, a serem seguidas pelos agentes de enfermagem na execução de um procedimento, com a finalidade especifica de racionalizar o trabalho, economizar tempo e movimento, aumentar a produção e diminuir gastos (Almeida, 1986, Collet, 1995).

Um dos procedimentos de enfermagem voltado para a manutenção do ambiente terapêutico é a Limpeza de Unidade do Paciente, com a preocupação fundamental de higiene e estética. A unidade do paciente tem sido definida como o conjunto de espaços e móveis destinados a cada paciente, variando os seus componentes de hospital para hospital. Basicamente, a unidade é composta por: cama, colchão, mesa de cabeceira equipada com material de uso pessoal, cadeira, escada e campainha (Kawamoto; Fortes, 1986, Sordi; Nunes, 1988, Souza, 1976, Torres; Lisboa, 1999).

A literatura tradicional de enfermagem distingue dois tipos de Limpeza de Unidade: a limpeza concorrente e a terminal. A Limpeza Concorrente é realizada diariamente, em algumas partes da unidade do paciente e objetos de uso pessoal, após os cuidados higiênicos e de rotina prestados (Torres; Lisboa, 1999). Já a Limpeza Terminal tem sido considerada aquela realizada quando o paciente desocupa o leito por motivo de alta, óbito, transferência ou em casos de hospitalização prolongada (Sordi; Nunes, 1988, Souza, 1976, Torres; Lisboa, 1999).

Esses tipos de limpeza são realizados para a remoção da sujidade e fundamentalmente para impedir a disseminação de microrganismos que colonizam principalmente as superfícies horizontais dos mobiliários, dentre eles o Staphylococcus aureus, Pseudomonas $s p$, Escherichia coli, Proteus sp e Serratia marcencens (Ayliffe, 1984), como também para proporcionar conforto e segurança ao paciente.

No processo de Limpeza de Unidade do paciente tem sido recomendado a utilização de produtos químicos (desinfetantes) eficazes para a obtenção da remoção e destruição dos microrganismos existentes nas superficies. Essa indicação e sua utilização têm levado, inclusive, a uma mudança de terminologia de Limpeza de Unidade para Desinfecção da Unidade ou de Superficies, já evidenciada na literatura (BRASIL, 1994, Torres; Lisboa, 1999).

Vários desinfetantes têm sido indicados nesse sentido, devendo os mesmos possuir princípios ativos fenólicos, compostos orgânicos e inorgânicos liberadores de cloro ativo, iodo e derivados, quaternários de amônia, alcoóis e biguamidas e outros princípios que atendam à legislação específica (BRASIL, 1992, BRASIL, 1994, Diaz; Rocha, 1996).

É importante atentar que essas considerações não descartam a necessidade de se observar o fato de que a efetividade do processo de desinfecção da unidade do paciente requer do pessoal envolvido com esta atividade, conhecimentos quanto às condições que interferem na ação dos produtos, à padronização dos uso e às normas de aquisição dos mesmos.

Nesta perspectiva, surge a figura do enfermeiro, profissional ainda responsável por esta atividade na maioria das instituições hospitalares, que deve se sentir igualmente compromissado com a manutenção de um ambiente seguro tanto para o paciente como para o pessoal sob sua responsabilidade e estar atento para cada um dos aspectos particulares desse compromisso, dentre os quais incluem-se aqueles relacionados à supervisão das atividades realizadas pelo seu pessoal. Essa supervisão como instrumento de avaliação, poderá se constituir em um indicador das necessidades de orientação, atualização e reciclagem, a fim de permitir em tempo hábil, a adoção de medidas corretivas necessárias.

Diante de todas essas considerações é que se propõe neste trabalho, avaliar a situação 
do procedimento de limpeza de unidade do paciente, através do conhecimento do enfermeiro responsável pelo Serviço de Enfermagem de alguns hospitais do interior do Estado de São Paulo, de modo a detectar, apontar e alertar sobre as possiveis falhas nesse processo de limpeza.

\section{MATERIALE MÉTODOS}

Para atender aos objetivos propostos por este estudo, foram entrevistados enfermeiros responsáveis pelo Serviço de Enfermagem de 23 hospitais de seis grandes cidades do interior do Estado de São Paulo. A seleção dos hospitais foi feita em função da facilidade de acesso às pesquisadoras. Além da facilidade de acesso não foi utilizado nenhum outro critério de inclusão ou exclusão dos mesmos, com exceção da possibilidade de recusa do enfermeiro em participar.

As entrevistas foram realizadas sempre por uma das autoras que para tal utilizava um roteiro estruturado em duas partes: $1^{\mathrm{a}}$ - dados relacionados a características da Instituição Hospitalar e $2^{\mathrm{a}}$ - com perguntas abertas: -Quem realiza o procedimento de Limpeza de Unidade?; Como é realizado o procedimento de Limpeza de Unidade?; Quando é realizado o procedimento de Limpeza de Unidade?

As perguntas foram direcionadas basicamente no sentido de se obter subsídios para a detecção das possiveis falhas no processo de Limpeza de Unidade, a saber: "quem realiza"o procedimento, "como e qual"o produto é utilizado para a sua execução e "quando" é realizada a Limpeza de Unidade.

Inicialmente, os enfermeiros foram orientados sobre os objetivos do estudo, relevando-se a importância de sua participação, o sigilo da identificação pessoal, bem como da instituição.

As respostas foram registradas no momento da entrevista, tomando-se o cuidado de anotar exatamente o que foi respondido, garantindo-se assim que as mesmas estivessem completas e suficientes. Quando da obtenção das informações, foi solicitado dos enfermeiros que excluissem aquelas relacionadas ao procedimento realizado em áreas críticas como Centro Cirúrgico, Recuperação, U.T.I., Berçários e outros, por se caracterizarem como áreas que normalmente recebem tratamentos específicos. Paralelamente foram levantados alguns dados relacionados à instituição, no sentido de melhor caracterizá-la e de possibilitar possíveis relações.

\section{RESULTADOS E DISCUSSÃO}

Os dados serão apresentados e discutidos conforme a seqüência das perguntas préestabelecidas. Inicialmente caracterizaremos os hospitais envolvidos neste estudo, conforme Tabela 1.

TABELA 1- Classificação dos hospitais segundo órgão mantenedor, tipo de assistência Ao se considerar o órgão mantenedor, número de leitos e tipo de assistência prestada

\begin{tabular}{|c|c|c|c|c|c|c|}
\hline \multirow{3}{*}{$\begin{array}{c}N^{\circ} \\
\text { DE } \\
\text { LEITOS }\end{array}$} & \multicolumn{4}{|c|}{ TIPO DE HOSPITAL } & \multirow{2}{*}{\multicolumn{2}{|c|}{ TOTAL. }} \\
\hline & \multicolumn{2}{|r|}{ PÚBLICO } & \multicolumn{2}{|c|}{ PRIVADO } & & \\
\hline & GERAL & ESPECIALIZADO & GERAL & ESPECIALIZADO & $\mathrm{N}^{\circ}$ & $\%$ \\
\hline Até 50 & 0 & 0 & 2 & 0 & 2 & 8,7 \\
\hline Até 150 & 0 & 3 & 11 & 0 & 14 & 60,9 \\
\hline 150 a 500 & 4 & 1 & 1 & 1 & 7 & 30,4 \\
\hline $\begin{array}{l}\text { Acima } \\
\text { de } 500\end{array}$ & 0 & 0 & 0 & 0 & 0 & 0,0 \\
\hline TOTAL & 4 & 4 & 14 & 1 & 23 & 100,0 \\
\hline
\end{tabular}


pelos hospitais, pode-se observar que a maioria dos mesmos $(60,9 \%)$ caracteriza-se como de médio porte (com até 150 leitos), dos quais $78,6 \%$ são de caráter privado e com assistência do tipo geral. Observa-se também que a maioria $(71,4 \%)$ dos hospitais de grande porte é do tipo público e geral.

Em relação às perguntas norteadoras da entrevista, relacionadas a quem realiza a Limpeza de Unidade, qual o procedimento e os produtos utilizados e quando a mesma é realizada, obteve-se como resposta à primeira que, em $34,8 \%$ dos hospitais esta atividade está a cargo do Serviço de Limpeza do próprio hospital ou de alguma empresa particular. Nos demais a responsabilidade fica a cargo do Serviço de Enfermagem. Vale considerar que embora a responsabilidade e a execução do procedimento naqueles hospitais estejam a cargo do Serviço de Limpeza, o qual não é da responsabilidade da enfermagem, em $25,0 \%$ deles o referido Serviço de Limpeza está subordinado diretamente à enfermagem, recebendo dela as orientações e supervisão necessárias.

Dos hospitais onde a atividade ainda é de responsabilidade do Serviço de Enfermagem, $20,0 \%$ estão em vias de transferi-la para o setor de limpeza. As justificativas foram variadas, indo desde a sobrecarga de atividades, a falta de pessoal e o desvio de prioridade de funções, ou seja, a indicação de um funcionário para executar um cuidado indireto em detrimento do cuidado direto.

São inúmeras as citações de enfermagem a respeito da insatisfação dos enfermeiros com as funções desempenhadas, com as péssimas condições de trabalho, baixos salários, dentre outros. Entretanto, acreditamos que a solução da problemática supracitada não deve ser uma simples transferência de atividade, sem critérios, de um setor para outro, mas que tal transferência deva estar apoiada na regulamentação do exercício de enfermagem que prevê, dentre as responsabilidades do enfermeiro, " a prevenção e controle sistemático da infecção hospitalar e doenças transmissiveis em geral, assim como a prevenção e controle de danos que podem ser causados à clientela durante a assistência de enfermagem" (BRASIL, 1986).

A nosso ver, ainda que a Limpeza de Unidade seja considerada um procedimento predominantemente manual e qualificado como um cuidado indireto, esses não devem ser motivos para que a enfermagem deixe de executá-lo. Torna-se fundamental que os enfermeiros reflitam e façam uma avaliação do seu verdadeiro papel nesta atividade, de modo a assegurar o seu espaço na manutenção de um ambiente hospitalar seguro.

Ao se buscar a relação das informações sobre quem executa a atividade com o tipo de hospital e a assistência prestada, vale considerar que naqueles em que o procedimento tem sido realizado pelo pessoal do Serviço de Limpeza, $\mathbf{8 7 , 5 \%}$ dos mesmos são classificados como hospitais privados e gerais. Por outro lado, em todos os hospitais públicos (gerais ou especializados) a responsabilidade pelo procedimento ainda permanece com o Serviço de Enfermagem, bem como no único hospital considerado privado e especializado.

É importante considerar que dos hospitais onde a Limpeza de Unidade ainda é realizada pelo Serviço de Enfermagem, 20,0\% evidenciaram interesse em estar transferindo esta responsabilidade para o Serviço de Limpeza. Esta constatação levou-nos a questionar quais seriam os motivos desencadeadores desta postura frente ao procedimento. Os motivos estariam ligados à questão econômica; à escassez de pessoal de enfermagem; ao fato de ser a Limpeza de Unidade considerada uma atividade puramente manual e desprestigiada? Esses questionamentos, apesar de não terem sido objetos do estudo, a nosso ver mereceriam uma análise para melhor compreensão do mesmos.

Em relação à questão orientadora como é feita a Limpeza de Unidade e que produto é utilizado para a sua execução, a análise das respostas evidenciou que $80,0 \%$ do entrevistados referiram sentir dificuldade de responder como é feita, uma vez que o procedimento não tem sido realizado com supervisão do enfermeiro. Esta situação foi evidenciada, principalmente, nos hospitais cuja atividade fora transferida para o Serviço de Limpeza. Referiram também que 
na maioria da vezes a "técnica tradicional"(segundo eles, aquela recomendada pela literatura) não tem sido cumprida fielmente, justificando ser trabalhosa, demorada e extremamente cheia de detalhes. Por outro lado reconheceram que o ideal seria a realização do procedimento segundo as normas preconizadas pela literatura.

Pelo levantamento das referências bibliográficas relacionadas ao procedimento e a sua execução, constatamos que na literatura norte-americana o assunto é pouco abordado, talvez por não recomendarem a aplicação rotineira da desinfecção de superfícies e por não encontrarem um evidência direta correlacionando o grau de contaminação ambiental com o risco de se contrair uma infecção (Dauschner; Fahlberg, 1982). Já em nossa realidade, apesar de ainda se colocar muita ênfase na desinfecção de superfícies, como uma medida efetiva na redução das taxas de infecções nos hospitais, a literatura de enfermagem parece demonstrar um certo descaso em relação ao assunto, uma vez que o mesmo tem sido pouco mencionado nas publicações mais recentes. Vale considerar ainda que o assunto demonstre uma estagnação no conhecimento este tem sido o referencial utilizado na atualidade para o ensino de enfermagem, nos seus diferentes níveis (Souza, 1976, Teixeira, 1962).

Analisando algumas das padronizações do procedimento na literatura, observa-se que existe uma preocupação em detalhar todos os passos a serem desenvolvidos, visando sempre a eficiência, a eficácia e a diminuição do desgaste físico. Esses passos da técnica geralmente são acompanhados apenas do material necessário para sua execução, que em alguns casos extrapola o que tem sido recomendado (ex: sapólio), não especificando a natureza da solução desinfetante e nem os princípios científicos a serem considerados durante o desenvolvimento do procedimento.

O depoimento abaixo, ilustra as colocações supracitadas:

Sabemos que compete ao enfermeiro, de forma direta, observar e manter a qualidade da Limpeza de Unidade do paciente, entretanto, devido a vários fatores da realidade hospitalar, é comum a realização da técnica e o uso de materiais de forma inadequados.

Em resposta à pergunta orientadora sobre o produto utilizado para realização da de Unidade Limpeza, deparou-se com uma diversidade de alternativas, conforme a Tabela2.

TABELA 2 - Distribuição dos produtos utilizados na Limpeza de Unidade do paciente, segundo a classificação dos hospitais.

\begin{tabular}{|c|c|c|c|c|rr|}
\hline \multirow{2}{*}{$\begin{array}{c}\text { PRODUTOS } \\
\text { UTILIZADOS }\end{array}$} & \multicolumn{3}{|c|}{ TIPO DE HOSPITAL } & \multicolumn{2}{c|}{ TOTALO } & \multicolumn{2}{c|}{ PRIVADO } & \multicolumn{2}{c|}{ TOTAL } \\
\cline { 2 - 8 } & GERAL & ESPECIALIZADO & GERAL & ESPECIALIZADO & $N^{\circ}$ & $\%$ \\
\hline Fenol sintético & 4 & 1 & 2 & - & 7 & 30,4 \\
\hline $\begin{array}{c}\text { Não sabia } \\
\text { informar }\end{array}$ & - & - & 9 & 1 & 10 & 43,5 \\
\hline $\begin{array}{c}\text { Agua + sabão } \\
+ \text { Álcool 70\% }\end{array}$ & - & 1 & 3 & - & 4 & 17,4 \\
\hline Água + sabão & - & 2 & - & - & 2 & 8,7 \\
\hline TOTAL & 4 & 4 & 14 & 1 & $\mathbf{2 3}$ & 100,0 \\
\hline
\end{tabular}

Numa primeira avaliação observa-se que do total de hospitais, $43,5 \%$ dos enfermeiros entrevistados não souberam informar o produto utilizado para a realização da Limpeza de Unidade do paciente. É importante considerar que todos os respondentes eram oriundos de hospitais privados, dos quais $90,0 \%$ ofereciam assistência geral e que nesta alternativa foram incluídas as respostas em que os enfermeiros, embora com dúvida, referiram ao hipoclorito de sódio, álcool etílico, fenol sintético ou então, alegaram que seguiam as recomendações do Ministério da Saúde, sem especificar qual o produto utilizado.

Um aspecto que merece consideração nesta análise é o fato de que $34,8 \%$ dos 
entrevistados referiram que nos hospitais estudados a realização da Limpeza de Unidade fica a cargo do Serviço de Limpeza e não do Serviço de Enfermagem, motivo que pode justificar o elevado percentual de enfermeiros desinformados em relação ao produto utilizado.

Outra avaliação passivel de se visualizar é em relação ao uso do fenol sintético, que foi a segunda alternativa em freqüência $(30,4 \%)$. Ao se considerar o tipo de órgão mantenedor da instituição, observa-se que $71,4 \%$ dessas informações advieram-se das de hospitais públicos. Por outro lado, a utilização de água, sabão e álcool etílico foi mais freqüente em hospitais privados $(75,0 \%)$.

Esses resultados levaram-nos a algumas reflexões sobre questões relacionadas ao custo e à eficiência dos produtos utilizados pelos hospitais o que, indiretamente, induziram-nos a concluir sobre a necessidade de se pesquisar a forma de utilização desses produtos (estarão sendo utilizados conforme recomendação do fabricante?).

Os germicidas têm sido amplamente utilizados em ambientes hospitalares para a obtenção da remoção e destruição de microrganismos existentes em superfícies, equipamentos e outros materiais. Por se constituírem em um importante componente dentro do orçamento hospitalar, tem sido recomendado a análise de sua ação antimicrobiana com base nos resultados de testes microbiológicos, com o intuito de se verificar se o produto é realmente capaz de eliminar os microrganismos. Esses testes de avaliação são classificados em preliminares "in vitro" e práticos e em condições de uso (realizados sob condições que procuram reproduzir o seu emprego na rotina), atendendo as especifícidades locais, o tipo de aplicação a que se propõem e o princípio de que o desinfetante para uso em superfícies ou instrumentos, não deve conter microrganismos viáveis (Christensen, 1982, Gontijo Filho; Romão, 1986). Esse controle tem ficado a cargo das Comissões de Controle de Infecção Hospitalar dos hospitais, que deveriam realizar levantamentos periódicos para acompanhamento da efetividade dos produtos frente aos microrganismos isolados na realidade hospitalar. É importante considerar, no entanto, que embora seja o mais rigoroso, o teste de campo tem sido pouco utilizado, em virtude das dificuldades de padronização para sua execução.

Os registros desses produtos têm sido regulamentados, em vários países, por órgãos federais ou entidades que controlam, estabelecem especificações e determinam os métodos microbiológicos para a sua avaliação.

Em nosso meio, a regulamentação fica a cargo do Ministério da Saúde, através da Divisão de Saneantes Domissanitários (DISAD). Em termos de legislação, existe a portaria ${ }^{\circ}$ 930, de 27 de agosto de 1992, do Ministério da Saúde (BRASIL, 1992), voltada para o combate às infecções hospitalares, em cujo anexo V (Normas para a limpeza, desinfecção, esterilização e antisepsia em estabelecimentos de saúde) apresenta apenas a classificação dos agentes químicos, sem ressaltar a importância da comprovação da eficácia dos produtos através de testes microbiológicos.

Atualmente, os produtos indicados pelo Ministério da Saúde para desinfecção de superficies fixas devem possuir os seguintes princípios ativos: fenol, quartenário de amônia, compostos orgânicos e inorgânicos liberadores de cloro ativo (hipoclorito de sódio, cálcio e lítio), iodo e derivados, alcoóis, biguamidas e outros compostos ativos que atendam à legislação específica (BRASIL, 1992, BRASIL, 1994). É importante considerar, no entanto, que apesar de o Ministério da Saúde especificar os produtos a serem utilizados na desinfecção de superfícies fixas, não estabelece claramente alguns critérios intrínsecos a cada produto, que direcionem sua utilização.

Apesar da variedade de princípios ativos, observa-se que o fenol sintético tem sido o mais utilizado pelos hospitais na realização da Limpeza de Unidade. Esta situação sugere uma possivel falta de fiscalização dos produtos em uso e de conhecimento por parte dos profissionais sobre outros produtos indicados para tal tipo de procedimento, bem como de pesquisas de campo que poderiam contribuir para uma melhor definição da relação custo-benefício. Esta situação vem ratificar o alto índice de respostas duvidosas ou de não conhecimento do produto 
utilizado (43,5\%), assim como de uso de produtos inadequados em unidades de internação (apenas água e sabão).

Achamos oportuno destacar os resultados microbiológicos obtidos por Angelo (1998) que evidenciou que a limpeza de unidade com fenol ao invés de diminuir a carga microbiana provoca o deslocamento dessa para outros pontos, resultando na manutenção da quantidade de microorganismo que existia anteriormente à limpeza.

Neste sentido, outros autores também mostraram que o fenol foi menos eficaz em comparação com outros produtos químicos desinfetantes (Navajas; Díaz; Castilho; Marin, 1992). Em resposta à pergunta quando é realizada a Limpeza de Unidade, observa-se pelos dados da Tabela 3 que a maioria dos enfermeiros $(56,5 \%)$ referiu que realiza apenas a limpeza terminal.

TABELA 3 - Distribuição das respostas emitidas pelos enfermeiros em relação a quando é feita a Limpeza de Unidade do paciente, segundo a classificação dos hospitais

\begin{tabular}{|c|c|c|c|c|c|}
\hline \multirow{3}{*}{$\begin{array}{c}\text { TIPO } \\
\text { DE } \\
\text { LIMPEZA }\end{array}$} & \multicolumn{4}{|c|}{ TIPO DE HOSPITAL } & \multirow[b]{2}{*}{ TOTAL } \\
\hline & \multicolumn{2}{|r|}{ PUBLICO } & \multicolumn{2}{|c|}{ PRIVADO } & \\
\hline & GERAL & ESPECIALIZADO & GERAL & ESPECIALIZADO & $\mathrm{N}^{\circ} \%$ \\
\hline Terminal & 1 & 2 & 9 & 1 & $13 \quad 56,5$ \\
\hline Concorrente & - & - & - & - & -- \\
\hline $\begin{array}{c}\text { Terminal e } \\
\text { Concorrente }\end{array}$ & 3 & 1 & 3 & 3 & 30,4 \\
\hline $\begin{array}{c}\text { Segue } \\
\text { recomendação } \\
\text { da literatura }\end{array}$ & - & - & 1 & - & 4,3 \\
\hline $\begin{array}{c}\text { Não soube } \\
\text { informar }\end{array}$ & - & - & 1 & - & 4,3 \\
\hline $\begin{array}{l}\text { Só em casos de } \\
\text { contaminação }\end{array}$ & - & 1 & - & - & 4,3 \\
\hline TOTAL & 4 & 4 & 14 & 1 & 100,0 \\
\hline
\end{tabular}

Vale considerar que $30,4 \%$ dos enfermeiros responderam de forma completa uma vez que referiram a limpeza de unidade terminal e a concorrente da unidade do paciente. Isso sugere, de certa forma, que esses enfermeiros tinham conhecimento das diferenças entre os dois procedimentos e dos momentos de suas realizações.

Lembramos aqui que a limpeza concorrente é aquela realizada diariamente, após a arrumação da cama e que consiste na limpeza de parte do mobiliário da unidade do paciente que, basicamente, é composta por: cama, colchão, mesa de cabeceira equipada com material de uso pessoal, cadeira, escada e campainha. Já a limpeza terminal tem sido considerada como a realizada quando o paciente desocupa o leito por motivo de alta, óbito, transferência ou em casos de hospitalização prolongada (Sordi; Nunes, 1988, Souza, 1976, Torres; Lisboa, 1999).

É importante considerar que apesar de serem definidas de forma a existir uma diferenciação entre ambas, na maioria das referências relativas ao assunto, não se obsenva uma descrição detalhada de procedimentos distintos que permita ratificar esta diferenciação. Geralmente é feita a diferenciação conceitual, acompanhada da descrição de apenas um procedimento, hipervalorizando a limpeza terminal.

Outra consideração a ser feita é que normalmente não definem a periodicidade da realização da limpeza terminal, nas situações em que o paciente permanece no leito por tempo prolongado, o que demostra a necessidade da realização de estudos para melhor definição deste intervalo, garantindo maior segurança para o paciente e para o responsável pela execução do procedimento.

Do total de respostas em relação a quando é feita a Limpeza de Unidade, $12,9 \%$ dos enfermeiros não citaram nenhum dos tipos de limpeza recomendados, protegendo-se em 
respostas evasivas do tipo "segue a recomendação da literatura", "só em caso de contaminação", ou não souberam sequer informar.

\section{CONCLUSÕES}

Ao se pretender conhecer a situação da Limpeza de Unidade do paciente em alguns hospitais do interior do Estado de São Paulo, através de depoimentos de enfermeiros responsáveis pelo Serviço de Enfermagem, verificou-se pelos resultados apresentados que a Limpeza de Unidade apesar de na sua origem ter sido reconhecida e mantida sob a responsabilidade do pessoal de enfermagem, atualmente tem sido relegada pelo mesmo, nos hospitais investigados. Observa-se que a enfermagem tem "aceitado" a transferência dessa responsabilidade para outros serviços, sem critérios e sem questionamentos, protegendo-se com justificativas que vão desde a sobrecarga de atividades, falta de pessoal, passando pela questão do desvio de funções, ou seja, a execução de um cuidado indireto em detrimento do direto.

No que se refere à maneira de execução do procedimento observa-se que a maioria dos enfermeiros sentiu dificuldade ou não soube informar. Esta situação parece estar relacionada com a anterior, que demonstrou um afastamento do enfermeiro desta atividade manifestado, inclusive, pela pouca ou nenhuma supervisão dos que o executam. No entanto, os enfermeiros referiram que o procedimento é extremamente cheio de detalhes, trabalhoso e demorado, quando cumprido fielmente, apesar de reconhecerem que a sua realização deveria ser segundo as normas preconizadas pela literatura.

Os resultados dos depoimentos demonstraram também que a maioria dos enfermeiros não soube informar o produto usado quando da realização da Limpeza de Unidade referindo, ainda que com dúvidas, o uso de hipoclorito de sódio, álcool etílico, fenol sintético ou que seguiam a recomendação do Ministério da Saúde. Pode-se observar que o fenol sintético tem sido o produto químico mais utilizado pelos hospitais na realização da Limpeza de Unidade, demonstrando uma possivel falta de conhecimento dos mesmos sobre a variedade de outros princípios ativos indicados por este Ministério. Nesse sentido, pesquisas de campo poderiam contribuir para uma melhor definição da relação custo-benefício dos variados produtos indicados e da utilização segura e adequada dos mesmos. Esta conduta poderia ser justificada pelo fato de que a negligência em relação à escolha de germicidas envolve sérios riscos, pela possibilidade do emprego de produtos com atividades não satisfatórias ou mesmo nula e até pelo risco de contaminação bacteriana dos mesmos, com conseqüente transformação em veículos de infecção.

Embora a literatura recomende a realização da Limpeza de Unidade em dois momentos distintos, ou seja, diariamente (Limpeza de Unidade Concorrente) e após a desocupação do leito pelo paciente ou em casos de hospitalização prolongada (Limpeza de Unidade Terminal), os resultados do estudo demonstraram uma hipervalorização pelos enfermeiros da Limpeza Terminal, em relação à Limpeza Concorrente. Esta supervalorização pode estar associada a um possivel "esquecimento ou desconhecimento" dos mesmos em relação aos tipos de Limpeza de Unidade, atendendo a sua periodicidade. Por outro lado é importante salientar que a própria literatura, ao mesmo tempo que classifica os dois tipo de Limpeza de Unidade, nem sempre aborda a sua execução de maneira distinta.

A análise de todos esses resultados deixa antever uma possível falta de investimento técnico-científico nos aspectos relacionados à Limpeza de Unidade, apesar de a mesma ser considerada um importante requisito para a manutenção de um ambiente biologicamente seguro para o paciente e para a instituição como um todo.

Esta situação possibilita questionamentos e reflexões acerca do compromisso e do envolvimento que administradores de instituições de saúde e profissionais afins têm demonstrado em relação à temática. A avaliação da qualidade de uma instituição tem passado por questões relacionadas a recursos técnicos, serviço de hotelaria, nível técnico do corpo clínico e de 
enfermagem, dentre outros. Neste sentido, é importante que as instituições tracem um perfil de sua realidade, principalmente no que tange ao Serviço de Enfermagem, uma vez que o mesmo se constitui no maior contingente de pessoal, executando também maior volume de ações na assistência prestada ao paciente. Ao mesmo tempo, esse pessoal desempenha um importante papel na prevenção e controle de danos que possam vir a ser causados aos pacientes, dentre eles a infecção hospitalar, papel este já previsto na própria regulamentação do exercício profissional. Por outro lado, não se pode deixar de considerar que o enfermeiro, enquanto responsável pelos demais integrantes do Serviço de Enfermagem, deve atentar para a necessidade de adequar o seu saber dentro do fazer, através de soluções alternativas viáveis e passiveis de avaliações e para os aspectos particulares do seu compromisso para a manutenção de um ambiente biologicamente seguro, tanto para o paciente como para o seu pessoal.

\section{CONSIDERAÇÕES FINAIS}

Este trabalho contribuiu para revelar uma parcela da situação da Limpeza de Unidade do paciente em algumas instituições hospitalares e não teve a pretensão de esgotar o assunto. A nosso ver ele se constituiu em um alerta para a necessidade de inovação e/ou de busca de fundamentação dos aspectos relacionados ao procedimento de Limpeza de Unidade, a fim de assegurar a manutenção de um ambiente seguro e saudável tanto para o paciente como para toda a equipe de saúde.

Não resta dúvida que as divergências, as discussões sobre condutas e/ou procedimentos, bem como, a procedência e validade das normas técnico-administrativas podem e devem ser equacionadas, sem perder de vista que o alvo da atenção é a segurança do paciente, que em nenhum momento pode ser prejudicada.

\footnotetext{
ABSTRACT: The objective of this investigation is to evaluate the procedure used for disinfecting patients' rooms, as well as to detect and indicate possible mistakes in this process. The results obtained through interviews with nursing professionals responsible for the Nursing Services reveal that the procedures used in the studied hospitals are not following the principles required by the literature. As a consequence there is little reliability concerning disinfecting procedures in those hospitals.
}

KEYWORDS: patients' rooms, disinfecting, hospital infection

RESUMEN: Este estudio pretende evaluar la limpieza de la unidad del paciente, asi como detectar, señalar y alertar sobre posibles fallas en el proceso de limpieza. Los resultados que se obtuvieron, mediante entrevistas con los enfermeros responsables por el Servicio de Enfermeria, revelan que los servicios de limpieza desarrollados en las unidades del paciente -de los hospitales en estudio, no está atendiendo a las normas preconizadas en la literatura. Ello acarrea un producto final con poca confiabilidad desde el punto de vista de la desinfección.

PALABRAS CLAVE:limpieza de la unidad del paciente, desinfección, infección hospitalaria

\section{REFERÊNCIAS BIBLIOGRÁFICAS}

AYLIFFE, G. A. J. Princípios para la desinfcción en un hospital. Laboratório, n. 78, p. 2223-235, 1984. ALMEIDA, M.C.P. O saber de enfermagem e sua dimensão prática. São Paulo: Cortez, 1986. 
ANGELO, D. D. A manutenção de um ambiente hospitalar biologicamente seguro: avaliação microbiologica dos leitos de um hospital geral antes e depois de sua limpeza terminal. Ribeirão Preto, 1998.126p. Tese (Doutorado). Escola de Enfermagem de Ribeiräo Preto, Universidade de Säo Paulo.

AYLIFFE, G.A.J. Principios para la desinfección en un hospital. Laboratório, n.78, p.223-235, 1984.

BRASIL. Leis etc. Lei $n^{\circ} 7498$ de 25 de junho de 1986. Dispõe sobre a regulamentação do exercício da enfermagem e dá outras providências. Diário Oficial da União, Brasília, 26 de junho. 1986. Seção 1, p. 9273 - 9275.

BRASIL, Leis, etc. Portaria $n^{\circ} 930$ de 27 de agosto de 1992. Dispõe sobre o serviço de controle de infecções hospitalares. Diário Oficial da União, Ministério da Saúde, Brasilia, 4 de setembro de 1992. Seçäo 1, p. 12.279 à 12.281.

BRASIL. Ministério da Saúde. Coordenação de Controle de Infeç̧ão Hospitalar. Processamento de artigos e superfícies em estabelecimentos de saúde. 2. ed. Brasilia, 1994

CHAIRPERSON, J.B.G. Nursing theories: the base for professional nursing practice. New Jersey: Prentice-Hall, 1980.

CHRISTENSEN, E.A. et al. In use testes of desinfectants. Acta. Path. Microbiol. Imunol. Scand. Sect. B., v. 90, p. $95-100,1982$.

COLLET, N. Transformações no ensino das técnicas em enfermagem pediátrica. Ribeirão Preto. 1995. 186p. Dissertação (Mestrado) - Escola de Enfermagem de Ribeirão Preto, Universidade de São Paulo.

DAUSCHNER, F; FAHLBERG, W.J. Floor desinfection in the United States. InfectionControl, n.3, p. $281,1982$.

DIAZ, C.A.A.; ROJAS, F.J.C. Proceso de limpeza en el hospital. Todo Hosp. n.126, p. 49- 53, 1996.

GONTIJO FILHO, P.P.; ROMÃO, C.M.C.P. de A. Testes microbiológicos e o registro de sanificantes, desinfetantes e antisépticos junto a Secretária Nacional de Vigilância Sanitária. $\underline{\text { Rev }}$ Microbiol, São Paulo, v.17, n.2, p.143-147, abr./jun. 1986

KAWAMOTO, E. E.; FORTES, J.I. Fundamentos de enfermagem. São Paulo: E.P.U., 1986. Cap.4, p. 15 20.

NAVAJAS, R.F.G.; DIAZ, R.M.; CASTILHO, A.S.C.; MARIN, M.A.I.; Concentraciones minimas inibitórias y bactericidas de algunos antisépticos y desinfectantes frente a cepas de origen hospitalario. Rev. Lat-Amer. Microbiol., v.34, p.1-6, 1992.

NIGHTINGALE, F. Notas sobre enfermagem: o que é, o que não é. São Paulo: Ed. Cortez, 1989.

SORDI, M.R.L.; NUNES, M.A.G. Manual básico de enfermagem. Campinas: Papirus, 1988. Cap. 1, p. 11-34.

SOUZA, E.F. Novo manual de técnica de enfermagem. São Paulo: Médicas, 1976. Cap. 4, p.34-51

TEIXEIRA,R.B. Manual do auxiliar de enfermagem: noções gerais e práticas. 2.ed. São Paulo: Edipe - Artes Gráficas, 1962. p. 266-268.

TORRES, S; LISBOA, T.C. Limpeza, higiene e lavanderia hospitalar, São Paulo: CLR- Balieiro, 1999. p.28-57. 